\title{
Critical Discourse Analysis of Sexism in English Language
}

\section{Zhemin Chen}

The Engineering and Technical Collegeof Chendu University of Technology, Leshan, China tinaswansea@163.com

Keywords: Critical discourse analysis, Linguistic sexism, English

Abstract. Language is not only a tool for communication, but also a mirror of speaker's ideological. This research aims to use the analytical approach critical discourse analysis to reveal the sexism in English language and hopes to gradually eliminate sex discrimination in vocabulary and expression.

\section{Introduction}

Sexism is a common social phenomenon, which can be reflected in languages. This article firstly gives a brief introduction to the basic concepts namely sexism and critical discourse analysis (CDA), and demonstrates a general review on the phenomena of sexism in English language and analytic tools. Then it makes comments on some examples to indicate sexism existing in English using.

\section{The definition and the phenomena of sexism in English language}

According to Ruether (1993: 165), sexism is gender privilege of males over females. It is males primarily who have originated this form of oppression, benefited from it, and perpetuated it, legally and ideologically. In other words, it is a belief system based on the assumption that the physical differences between males and females are so significant that they should determine virtually social and economic roles of men and women.

Lakoff (1973) claims that woman experience linguistic discrimination in two ways, namely sex bias in language and sex difference in language use. There are abundant cases of sexism in English and its use, which has attracted the attention of feminist linguists. Schneider and Foss contend that English is biased in favor of the male in both syntax semantics (Spender, 1985: 14). Julia Stanley (1997) points out that there was no linguistic reason for this to be the case. She found that many of the words for woman had sexual overtones and despite the fact that there were more words for men, of smaller sample assigned to women there were 220 words for sexually promiscuous female and only 20 for sexually promiscuous male (as quoted in Spender, 1995: 15). All these indicate that the English language as a system embodies sexual inequality. The other evidences and examples of sexism in English language will be analyzed in the following parts.

\section{Theory and methods of CDA}

Critical discourse analysis (CDA) also named as critical linguistics or linguistic criticism, and is a type of discourse analytical research that primarily studies the way social power abuse, dominance, and inequality are enacted, reproduce, and resisted by text and talk in the social and political context. With such dissident research, CDA take explicit position, and thus want to understand, expose, and ultimately resist social inequality (Van Dijk, 2008: 85). CDA aims to provide a critical dimension in its theoretical and descriptive accounts of texts (Gunter Kress, 1985). Currently, CDA has become a vital force in modern language study. It focuses upon the linguistic elements of social interaction, and sets out to show up the hidden power relations. As to the specific analytical methods, different critical analysts may have different choices. This study will focus on four analytical tools which are transitivity, modality, transformation and classification.

Firstly, the transitivity system construes the word of experience into a manageable set of process types. Halliday (1994: 107) first identifies three principal types of processes in English clause: Material, Mental, and Relational. More specifically, material processes are processes of “doing”. 
They express the notion that some entity "does" something - which may be done "to" some other entity. Mental processes are processes of "feeling”, "thinking” and "perceiving”. It usually includes two participants: Sensor which is the conscious being that is feeling, thinking or seeing, and Phenomenon which is felt, thought or seen. Relational processes are processes of "being": something is said to be something else. In a word, the choice of process types could make the text unique. Whatever is chosen becomes the bridge between writers and readers. Thus, it is necessary for us to identify and sort out the different forms then infer how they realize or encode the meaning.

Secondly, modality plays a vital role in carrying out the interpersonal function of the clauses as exchange in English (Thompson 2004: 41). Noticeably, in English naming and addressing can express the meaning of mood. In Halliday's (1994: 76) system, modality is grammatical category of verbs, which expresses the subjective attitude of the speaker toward and the state of affairs described by the utterance.

The third one is transformation. Two specific transformations are particularly worth studying in sexism analysis: passivization and nominalization. Passivization allows a noun denoting an affected participant, a non-agent to be places in the subject position in a sentence. In some cases the real agent phrase is deleted completely, which has the effect of obfuscation and emphasis. As Fowler (1991: 80) observes, nominalization is a radical syntactic transformation of a clause, which has extensive structural consequences, and offers substantial ideological opportunities.

Finally, classification is an essential tool for critical analysis. There are two lexical features. One is reclassification, which is generating new wordings which are set up as alternatives to, and in opposition to, existing ones. It is a "sign" of "intense preoccupation", pointing to "peculiarities in ideology" of the group responsible for it (Fairclough, 1991: 193-194). Another feature is overclassification. It refers to the existence of an excess of quasi-synonymous terms for entities and ideas that are a particular preoccupation or problem in the culture's discourse. The above discussion is a theoretical account of the analytic tools, which will be applied to the next part.

\section{Critical discourse analysis of sexism in English}

In this part, the tools will be used to explore sexism in mass media. News is a common way for people communicating with each other today and it can reflect and influence readers' ideology. However, news reports have never been absolutely objective to some extent; it could be manipulated by some social powerful groups to seek for their own benefits. Therefore, readers should hold a critical language awareness to uncover the discriminations in the media.

Analysis of the transitivity. Transitivity has been divided into three process types: material process, mental process and relational process. Material process expresses the process of doing something which involves the "actor" and the "goal". Relational process indicates the relationship between the two participants or things. So material process emphasizes the behavior itself while relational process shows the relevant surrounding's status which can easily cover the actor and the way of an action. The following examples extracted from newspaper showed the use of the different characteristics between material process and relational process in order to disclose the imbalanced power between men and women.

\section{Houston Mother Kills 5 Children}

Family of Six Dead in Murder-Suicide(Associated Press)

Both of the above news titles are from the same media, but the implicit effected to readers totally different. In the first example, Associated Press employed a completely material process title which contains both the "actor" and the "goal". The "actor" (Houston Mother) has been put in the subject position and directly point to the "goal" (5 Children), and the material process has been completed by the verb "kills". In this case, the reader may have a strong sense of how cruel the mother is. Surprisingly, however, the latter one which came from the same media used relational process to express the title for the sake of eliminating the crime of the father. In this way the subject has been changed into "Family of Six" and the action became a status "are dead" instead of the verb "kill”. In 
other words, the author attempted to conceal the father's cruelness and to bedim the close relationship between the murder and the victim. The two examples indicated that women's image are more likely to be damaged while men's are incline to be protected and revealed the imbalanced power between men and women.

Analysis of the modality. Analysis of the modality can reveal the interpersonal relationships among the participants. Different forms of address reflected the speaker's ideology and can cause implied imbalance between men and women. See the following examples:

Of all the many faces Madonna presents to the world, the one she tries to disguise is that of successful businesswoman. The girl who arrived in New York with a fistful of dollars might become one of the richest women in the world. This sexy woman's fortune may be worth close to US 1000 million.

David Beckham's talent to bend free kicks around defensive walls and past goal keepers will soon be seen everywhere. This means this English soccer superstar will become a real global brand. The football star's advertising income should be more than US 100 million.

The first report is about Madonna became a successful businesswoman and the second report is about Beckham became a spokesman of a global brand. However, the media employed different forms of address when describe their success in career. When describing Madonna's success in business, there are three forms of address while two of them are associated with her appearance and gender identity, "The girl" and "This sexy woman" respectively. But the forms of address which highlight her success in business did not used in the report. On the contrary, when describing Beckham the report used "English soccer superstar" and "The football star" to give prominence to his success and better social status. From the analysis of the two different forms of address used in the report, the unequal can be seen in social status and power between men and women.

Analysis of the transformation. In this section passivization in the transformation will be analyzed to disclose men are tend to escape from their responsibility easily while women are more likely to getting hurt. There is an example:

His third victim, a 39-year-old mother of three, was attacked at gunpoint after Steed had forced her car off the M4. (The Sun)

The report described the crime with a passive form and in this way blurred the relationship between the "actor" Steed and the victim. In this case, it would easily mislead readers to consider that Steed did not have a direct connection with the woman but it was not the fact.

Analysis of the classification. Using words and phrases to classify things are usually seen in the media, and that could be a main factor of the phenomena of discrimination. In English, words that represent men are always positive while those are concerned with women are more often negative. For example, the word "governor" means who hold a supreme power to the army or lands, while the word "governess" refers to people who engaged in service profession. The difference showed the different social power between men and women. Besides, the offensive and discriminatory words used to describe women are much more than those to describe men. For example, cow, bitch, slut, chick, etc. From the analysis of the implied phenomena in English language, we can draw a conclusion that there is a great number of sexism against women. Therefore, people should pay more attention to it and to enhance the critical language awareness.

\section{Conclusion}

Sexism has been formed for a long time with the development of English language, which influences on our daily life and the way of thinking. People should focus on the choice of vocabulary and use gender-neutral term as much as possible. What's more, the readers could use CDA to explore the hidden sexism in English and finally eliminate discriminatory languages in today's society. 


\section{Acknowledgements}

This work was a Project Supported by Scientific Reserch Fund of SiChuan Provincial Education Department (15SB0266).

In addition, I deeply appreciate the contribution to this paper made by my friend Xie Jiaxu.

\section{References}

[1] Ruether, R. R: Sexism and God-talk: Toward a Feminist Theology (Beacon Press, America 1993).

[2] Lakoff, Robin: Language in Society, Vol.2 (1973) No.1, pp. 45-79.

[3] Spender, Dale: Man Made Language (Routledge, British 1985).

[4] Van Dijik, T.A: Discourse and Power (Palgrave Macmillan, British 2008).

[5] Gunther, Kress, in: A handbook of discourse analysis, edited by Teun A. Van Dijk, Ideological structures in discourse, Academic Press (1985).

[6] Halliday, M. A. K: An Introduction to Functional Grammar (Edward Arnold, British 1994).

[7] Thompson, G: Introducing Functional Grammar (Edward Arnold, British 2004).

[8] Fowler, R: Language in the News: Discourse and Ideology in the News (Routledge, British 1991).

[9] Faircologh, N: Language and Power (Longman, British 1991). 